\title{
Women experts underrepresented in pandemic coverage
}

\author{
— Cite as: CMAJ 2021 January 25;193:E143-4. doi: 10.1503/cmaj.1095916
}

Posted on cmajnews.com on January 8, 2021

W hile many Canadian health leaders are women, men have given most media interviews during the COVID-19 pandemic. According to data collected by Informed Opinions, a nonprofit organization dedicated to amplifying women's voices in the media, women comprised just $31 \%$ of sources quoted in major Canadian outlets since March last year.

"We are seeing mainly men from our field of medicine who are commenting across the spectrum, whether they are geriatricians, intensivists, epidemiologists or infectious disease doctors," says Dr. Lisa Richardson, vice-chair of culture and inclusion in the department of medicine at the University of Toronto. "There seem to be more men choosing to interact with the media."

As severe acute respiratory syndrome coronavirus 2 (SARS-CoV-2) vaccinations roll out while infections, deaths and misinformation continue to rise, Richardson says balanced representation in the media is critical to reflect the diversity of experiences in communities and hospitals across Canada. "It's important for people to see themselves represented in our profession."

Julie Carl, senior editor of the Toronto Star, says the public wants to know what the medical community is thinking and saying about COVID-19. Still, she acknowledges that the newspaper's expert sources comprise "mainly white guys."

Diverse voices enrich news coverage, but reporters are on tight deadlines, Carl explains. "The person who gets back to you first is the person who gets in the paper. We want accuracy first, but there is pressure for speed," she says. "Even if you can't answer the question right at that moment, get back to us and say, 'I am going to need a half-hour.' Then we know there is somebody on the line."

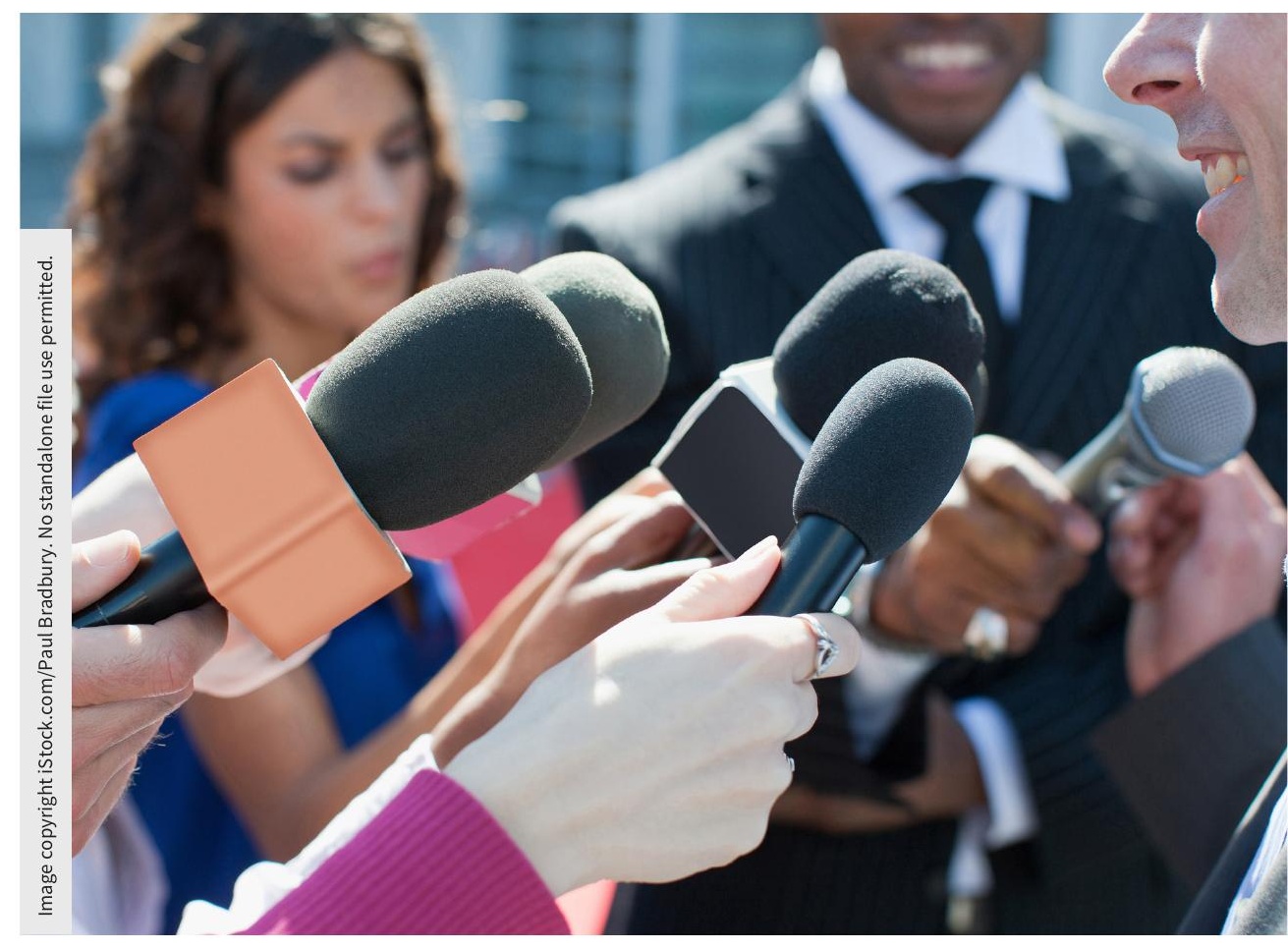

Two-thirds of the sources interviewed by major Canadian news outlets since the beginning of the pandemic were men.

Speed and time are factors limiting women's involvement with media, says Shari Graydon, a former CBC journalist and founder of Informed Opinions. "The time issue affects women more and differently than it affects men," says Graydon. "Women have demonstrably less time due to raising children and taking care of elderly parents."

But too little time is not the only factor, says Graydon. Women often tell her they are not the best person to interview and reporters should approach someone else, yet "that does not stop men."

"There is no one best person," Graydon says. And the women doubting themselves have the education, the capacity and "know enough to help the public make sense of an issue."

Dr. Alison Fox-Robichaud, past president of the Canadian Critical Care Society, says health care institutions and professional organizations should support women in engaging with media and ensure balanced representation in official communications.

The Canadian Critical Care Society recently enacted measures to help media outlets connect with female experts and ensure equal gender distribution of media invitations among the organization's executive board.

Fox-Robichaud and Richardson say hospitals and other medical organizations should also offer media training early in 
medical practice. "We don't get any training for how you work with the media," Fox-Robichaud says. "For any physician, female or male, if you are in a leadership position, media training is a central part of getting the message right."

Richardson says such training should specifically address common concerns raised by female medical professionals, including "imposter syndrome" worries and how to deal with sometimes vicious public scrutiny.

"I think we saw early on in the pandemic how women leaders were treated," says Richardson. "The mistreatment that
Dr. Teresa Tam experienced was appalling. The comments on her decision making, qualifications and background were very problematic."

Despite the potential for public criticism, Graydon says representation of women in prominent roles make a difference, and female health care professionals' voices are critical to amplifying pressing community concerns.

"We are $50 \%$ of the population and our perspectives are being reflected less than a third of a time. That has huge implications for what we prioritize as a society and culture, what governments invest money in, and our understanding of how significant issues like the pandemic are affecting women."

Dr. Catherine Varner, Toronto, Ont.

Content licence: This is an Open Access article distributed in accordance with the terms of the Creative Commons Attribution (CC BY-NC-ND 4.0) licence, which permits use, distribution and reproduction in any medium, provided that the original publication is properly cited, the use is noncommercial (i.e., research or educational use), and no modifications or adaptations are made. See: https://creativecommons.org/ licenses/by-nc-nd/4.0/ 